\title{
15
}

\section{Dilemas do exercício profissional no setor da saúde em Portugal}

Ana Paula Pereira Marques

ICS - PUMINHO

| Helena Rafaela Vieira Rosário UICISA - NUMINHO

Ana Paula Morais de Carvalho Macedo UICISA - NUMINHO 


\section{RESUMO}

Sob o efeito do Memorando da Troika (2011-2015), as políticas de saúde em Portugal conhecem uma agenda política, empresarial e organizacional orientada por princípios de privatização, desregulação e subfinanciamento dos serviços públicos por parte do Estado. Neste artigo, faz-se uma revisão da literatura sobre os sistemas de saúde dos países de Sul, destacando-se a situação portuguesa quanto aos processos de reforma e principais desigualdades de saúde antes e durante a crise económica. Complementarmente, convocam-se os testemunhos de diferentes profissionais do setor da saúde (médicos, enfermeiros, técnicos de terapêutica, sindicatos e dirigentes de unidades de cuidados). Baseado num estudo de trabalho de campo, de cariz exploratório, discutem-se as transformações político-organizacionais e suas consequências na desregulação e precarização das relações de trabalho no setor da saúde. Reduções salariais, congelamento de carreira, instabilidade contratual, desmotivação profissional, intensificação do ritmo de trabalho e desqualificação dos serviços são alguns dos sinais mais visíveis de uma agenda gestionária que conflitua com as missões de um Sistema de Saúde Pública (SNS) universal ao serviço da sociedade portuguesa.

Palavras-chave: Portugal, União Europeia, Desigualdades em Saúde, Política de Saúde, Pessoal de Saúde. 


\section{- INTRODUÇÃO}

Enquanto atividade económica sui generis no domínio produtivo e reprodutivo, o setor da saúde conheceu, nos anos oitenta e noventa do séc. XX, reformas alimentadas pelas tendências de descentralização, desregulação, privatização e mercantilização orientadas pelos princípios de "economia, eficácia e eficiência",,2,3. O processo de mudança tem sido designado frequentemente de reforma da política de bem-estar e desenvolvimento social característica de um Estado-Providência. Todavia, este enfrenta, paradoxalmente, desafios cada vez mais complexos e exigentes na capacidade de resposta a problemas de, por exemplo, envelhecimento e prevalência de multipatologias da população, ampliação e diversificação de formas e tipos de cuidados de saúde, recrudescimento de desigualdades sociais e territoriais de acesso e prestação de cuidados de saúde.

Com o agravamento da crise global e estrutural, a partir de 2008 até à atualidade, muitas das reformas prosseguidas nos países do Sul da Europa tendem a sustentar modelos de proteção social e desenvolvimento de políticas de saúde que aprofundam tendências de: i) privatização e sub-orçamentação por parte do Estado; ii) difusão de contratos de gestão privada orientada por imperativos de produtividade e externalização de serviços; iii) introdução de softwares e plataformas online que integram o exercício profissional nas diversas vertentes (desde gestão à interação com utentes e sociedade civil); iv) congelamento de carreiras e precarização dos vínculos laborais dos profissionais de saúde; vi) intensificação dos ritmos de trabalho, desvalorização salarial e proteção social; e v) constituição de fluxos emigratórios volumosos de profissionais qualificados do setor da saúde ${ }^{4,5}$.

É objetivo deste artigo analisar as transformações político-organizacionais na agenda para a saúde e suas consequências na crescente desregulação e precarização das relações de trabalho dos profissionais de saúde nos países do Sul da Europa, com enfoque em Portugal. Inicia-se por situar as transformações comuns a Portugal, Espanha, Itália e Grécia, e as razões que permitem justificar as proximidades a um modelo de Welfare State "corporativista", distanciando-os dos modelos prosseguidos pelos países do Centro e Norte da Europa. Aprofundando a realidade portuguesa, apresentam-se os eixos da agenda da saúde e seus propósitos reformadores nas últimas décadas e, em especial, no contexto de crise sob o Memorando da Troika (2011 e 2015). Este memorando traduz os termos negociados da ajuda financeira prestada a Portugal, tal como aconteceu a outros países da União Europeia, como Grécia, Espanha e Irlanda, sempre que o país não cumpre os limites da disciplina imposta aos Estado-membros, ou seja, apresenta um deficit orçamental superior a $3 \%$ do Produto Interno Bruto (PIB). Para terem esta ajuda financeira, o país alvo de ajuda financeira, tem que cumprir um programas de ajustamento estrutural, cujos contornos são definidos pelas instituições da Troika, que consiste num consórcio de credores compostos pela Comissão 
Europeia (CE), o Banco Central Europeu (BCE) e o Fundo Monetário Internacional (FMI). Regra geral, este programa de ajustamento estrutural assume contornos de austeridade, ao impor medidas de redução da despesa do Estado, com impactos económicos e sociais nas políticas públicas.

$\mathrm{Na}$ apresentação dos resultados, a discussão privilegia os pressupostos e princípios que suportam o ideário da implementação da New Public Management ${ }^{6}$, dando suporte ao argumento central de uma "desvalorização" da força de trabalho. Trata-se de um debate com crescente interesse na literatura internacional e nacional que tem destacado as várias dimensões de desregulação e precarização do mercado de trabalho (trans)nacional dos profissionais de saúde visíveis nas suas trajetórias e experiências profissionais dos últimos anos.

\section{- METODOLOGIA}

A escassez de estudos sobre esta temática permite-nos avançar com um desenho de pesquisa com contornos de um estudo exploratório. Inicia-se por uma revisão da literatura e pesquisa documental sobre os sistemas de saúde dos países do Sul, destacando-se a situação portuguesa quanto aos processos de reforma e principais desigualdades de saúde antes e durante a crise econômica. Utilizamos indicadores macroeconómicos mais relevantes ilustrativos das dimensões em análise pela consulta da OECD Health Statistics 2017 e de documentos enquadradores das principais reformas macroinstitucionais (e.g. Health 2020 Framework for Action, Global strategy on human resources for health: Workforce 2030). Para o caso português, analisou-se o Plano Nacional de Saúde (PNS- 2012-2016), entretanto revisto e alargado até 2020. Este Plano constitui um elemento basilar das políticas de saúde em Portugal e encontra-se estruturado em quatro eixos: i) Cidadania em Saúde, ii) Equidade e Acesso Adequado aos Cuidados de Saúde, iii) Qualidade na Saúde e iv) Políticas Saudáveis. Traça como metas fundamentais o aumento em 30\% da esperança de vida saudável aos 65 anos de idade e ainda a redução dos fatores de risco relacionados com as doenças não transmissíveis, nomeadamente o consumo e exposição ao fumo do tabaco e a obesidade infantil. Além deste documento, foram consultados documentos enquadradores das reformas, tais como os últimos cinco Relatórios do Observatório Português dos Sistemas de Saúde Nacional de Saúde (OPSS) e o Relatório da Fundação Calouste Gulbenkian - Um Futuro para a Saúde: todos temos um papel a desempenhar.

Em paralelo, procede-se à realização de trinta e duas entrevistas, intencionalmente aplicadas aos atores do setor da saúde, nove entrevistas semiestruturadas de dois hospitais da zona norte de Portugal (um hospital de gestão de Parceria Pública Privada e um hospital, de estatuto de Empresa), e posteriormente vinte e três entrevistas semiestruturadas a profissionais dos Cuidados de Saúde Primários (CSP) do norte, centro e sul do país. 
O procedimento para a realização das entrevistas obedeceu ao estabelecido em normas consensuais de defesa da dignidade e da integridade humanas, i.e., após a obtenção das autorizações dos participantes foi-lhes explicado e ficaram cientes de que os dados obtidos poderiam ser divulgados junto da comunidade acadêmica, respeitando o carácter confidencial das identidades.

As questões foram sistematizadas num guião pré-concebido pelas investigadoras do estudo, com temáticas orientadas para as vivências, percepções e expetativas que os diferentes profissionais no setor da saúde (individuais e coletivos) atribuem aos acontecimentos relacionados com a sua trajetória de vida e experiência profissional, na última década, sendo o mesmo utilizado com flexibilidade e adaptado ao perfil do/a entrevistado/a. Dois tópicos do guião foram desenvolvidos: i) acesso à profissão/ emprego; ii) a profissão e as mudanças no quadro da política portuguesa e como vê o futuro do seu trabalho (atual profissão)? Estes tópicos permitiram às investigadoras analisarem as transformações na agenda da política nacional de saúde, suas consequências no mercado de trabalho e trajetórias profissionais dos profissionais relacionados com o setor da saúde.

A recolha de dados aos participantes do estudo ocorreu no período compreendido entre dezembro de 2017 a janeiro de 2018.

\section{Bem-Estar Social Mediterrâneo e Desigualdades de Saúde}

O setor da saúde apresenta-se como uma atividade significativa da economia ao nível da União Europeia e intensiva em termos de (criação) de emprego. A pressão para a privatização, liberalização, desregulação e subfinanciamento dos serviços públicos por parte do Estado tem caracterizado as políticas de saúde em Portugal, bem como noutros países, como Grécia, Espanha e Itália. Comummente associados a um regime de bem-estar mediterrâneo, estes países tendem a ser subjugados aos ciclos incertos e cada vez mais voláteis das reestruturações da economia globalizada e de um ideário neoliberal.

Compreender os problemas associados à reforma e modernização do Estado Social afigura-se, como nos relembra Ferrera ${ }^{7}$, mais pertinente perante a crise estrutural que afeta com mais gravidade os Estados sociais da Europa do Sul, apesar de também os outros países conhecerem dificuldades crescentes de financiamento dos seus sistemas de saúde 8,9,10. Ainda assim, importa sinalizar os avanços significativos na melhoria da esperança de vida e da mortalidade infantil nestes países. Todavia, a persistência das desigualdades de saúde em função dos recursos materiais, educativos, status social e inscrição territorial, fazem deste tópico uma das áreas privilegiadas para a intervenção por parte dos decisores políticos.

No que diz aos países do Sul da Europa, em especial, Espanha, Grécia, Itália e Portugal, as reformas introduzidas nos sistemas nacionais de saúde, nas décadas de oitenta e noventa 
do século XX, não conseguiram eliminar os desequilíbrios territoriais e de universalização da capacidade de prestação dos cuidados de saúde. Esta maior fragilidade na consolidação do Estado social, por comparação a outros países do Norte da Europa, explica-se, por um lado, por razões político-institucionais e, por outro, pela densificação da crise econômica no quadro das políticas de austeridade impostas pela Troika a partir dos anos 2010-2011.

No contexto das razões político-institucionais, são convocados argumentos "geo-evolucionistas"7 que sustentam o relativo atraso do desenvolvimento do Estado Social nos países do Sul da Europa e do enfrentamento de meios socioeconómicos mais problemáticos. Tal condicionou, desde o início da sua implantação, sistemas de proteção social mais permeáveis à "permanente" austeridade e "subdesenvolvimento" institucional, assente num sistema de proteção social "dualista". Esta dualidade do sistema de proteção social baseia-se no regime de prestações muito generosas para as principais categorias do mercado de trabalho (empregados públicos e trabalhadores das grandes indústrias) e modestos esquemas de proteção para as categorias periféricas (trabalhadores precários, trabalhadores por conta própria e trabalhadores de pequenas empresas). Assim, tendem a ser persistentes problemas de irregularidade dos serviços públicos quanto à sua distribuição no território e à disponibilidade de recursos financeiros e humanos para enfrentarem as diversas categorias de problemas sociais (e.g. desemprego, risco de velhice e de pobreza, habitação social). Tal assume particular visibilidade no campo dos cuidados com a saúde, com a implementação de um serviço nacional de saúde que, associando os cuidados de saúde à cidadania universal, tem vindo a combinar instituições a atores sociais não públicos, assumindo particular importância a articulação público-privado. Por sua vez, nestes países e, em especial em Portugal, a existência de uma "sociedade providência"11 reforçou o papel da família, das redes de vizinhança e das comunidades locais. Estas suportam laços de interconhecimento e interajuda que permitem a troca de bens e serviços numa base não mercantil, funcionando como "almofada" na privação ou insuficiência de ajuda institucional (serviços de apoio, designadamente apoio domiciliar).

Nesta construção do Estado social consolidado ao longo da expansão do capitalismo keynesiano, Esping-Andersen identificou três "Welfare regimes"12, designadamente: o regime social-democrático dos países escandinavos; o regime conservador-corporativo, da Europa continental; e o regime liberal, dos países anglo-saxónicos. Integrando os países do Sul da Europa numa das variantes do modelo "conservador-corporativo", esta tipologia de modelos de Estado social foi alvo de críticas por vários autores ${ }^{6,13,14,15,16}$ que reforçaram a importância de se configurar um "quarto modelo", designado de "corporativista". Este último modelo fundamenta-se em fatores históricos, sociopolíticos, mas também na existência de governos autoritários, na influência da igreja católica e na elevada competição político-partidária ${ }^{17}$. 
Além disso, importa considerar as estratégias de profissionalização por parte dos médicos, face a outras categorias profissionais, com inegável poder de monopolização do mercado de trabalho e evitamento de usurpação do seu campo profissional e autonomia do "ato médico". A prevalência de um modelo hospitalocêntrico dos sistemas de saúde, em que as especialidades médicas assumem-se como a organização central do sistema de saúde, reforça este caracter "corporativista" destes países do Sul da Europa. Nesta divisão social do trabalho no setor da saúde, os médicos têm conseguido manter parte das suas prerrogativas profissionais, resistindo à erosão da sua autonomia e expertise perante a introdução dos princípios da nova gestão pública, afastando-se de uma tendência de fundo mais marcada nos países Escandinavos e da Europa Continental ${ }^{18,19}$. Portanto, para além de razões de carácter sociopolítica e histórica, são evocadas as razões político-jurídicas e ideológicas como denominador comum daqueles países de sul da Europa.

\section{Agenda das Políticas de Saúde e seus Propósitos Reformadores em Portugal}

O projeto político do Serviço Nacional de Saúde em Portugal, criado em 1979, tem conhecido diversas reformas no sentido de promover um serviço de saúde acessível a todos, com alta qualidade e sustentável economicamente. São vários os marcos que traçaram o desenvolvimento de políticas de saúde, ainda com muita intermitência e volatilidade em função dos quadros político-partidários da ação governativa, tais como: a implementação da Lei de Bases da Saúde em 1990 (em revisão no atual governo constitucional), a criação do Estatuto de Serviço Nacional de Saúde, em 1993, e o primeiro Plano Nacional de Saúde 2004-2010, seguindo as recomendações da União Europeia. Todavia, desde estas primeiras fases que são visíveis os problemas de subfinanciamento, a concentração de recursos no setor hospitalar, a pouca coordenação entre cuidados primários e secundários, a forte presença do setor privado orientado por princípios neoliberais, que condicionam desiguais oportunidades de acesso à saúde por parte de grupos populacionais mais vulneráveis economicamente.

Na primeira década do séc. XXI, o governo português avança com um conjunto de reformas, muitas delas ainda em curso, que visa uma profunda reestruturação ao nível dos sistemas de gestão e organização dos cuidados de saúde no contexto hospitalar e saúde primária. Parte significativa dos hospitais públicos foi transformada primeiro em Sociedades Anónimas (S.A.) e, logo depois, em Entidades Públicas Empresariais (E.P.E.), corporizando a tendência de empresarialização, incluindo, a privatização, a pressão para o cumprimento de requisitos de padrões de qualidade e externalização de serviços por via sobretudo das parcerias público-privadas ${ }^{20}$. Igualmente, cria-se uma rede nacional hospital através da concentração dos vários hospitais em Centros Hospitalares, permitindo uma gestão mais racional e eficiente do tipo de cuidados a prestar às populações. Cumpre-se, assim, um primeiro passo 
na reforma quanto à separação entre financiamento e prestação dos cuidados, a partir da contratualização entre Estado e hospitais públicos e a imposição de uma gestão por objetivos, e da progressiva transferência de serviços públicos para o setor privado. Simultaneamente, tem lugar à instauração de um mercado interno pela competição entre hospitais públicos e entre hospitais públicos e privados, disseminando-se instrumentos de gestão assentes em sistemas remuneratórios e vínculos contratuais distintos e incentivos ficais.

Quanto à reconfiguração de redes de cuidados de saúde primários e continuados, a Unidade de Saúde Familiar (USF) protagoniza a principal mudança e assume a "bandeira política do sucesso da reforma"21. Esta inscreve-se num sistema de contrato-programa onde se define o tipo e a quantidade de servidos e cuidados a prestar à população, estando o financiamento indexado ao cumprimento de um conjunto de indicadores e à padronização da prática do "ato médico". Paralelamente, a política de medicamento baseada na promoção do mercado de genéricos e no sistema de preços de referência, surge como resposta à pressão crescente para a contenção da despesa com os medicamentos, comum à maioria dos países da União Europeia. O aumento das despesas com a sobreprescrição ou práticas de prescrição inadequadas têm evidenciado limites a esta política quanto ao seu potencial de redução do crescimento da despesa pública e privada com os medicamentos a médio e longo prazo. Além disso, mantém-se as práticas de diminuição das comparticipações em medicamentos, aumento das taxas moderadoras, limitação da utilização de meios complementares de diagnóstico, entre outras.

\section{Nova Gestão Pública e Precarização das Relações de Trabalho}

A generalização dos princípios de mercado e consumismo, de um discurso gestionário e controlador explícito na lógica de resultados, qualidade e avaliação enformam a New Public Management ${ }^{1,6}$. Esta estratégia tem sido acompanhada por uma crescente precarização das relações do trabalho, com contratos individuais e flexíveis e agravamento do desemprego estrutural 22,23,24,25.

Esta transposição ou mimetização da lógica de gestão empresarial privada à "coisa pública", relacionada com a prestação de cuidados de saúde, tem, todavia, importantes consequências na composição da mão-de-obra, que, apesar de ser uma população altamente qualificada em termos de habilitações, encontra-se presentemente sujeita a uma dualização e segmentação significativa quanto aos processos de vinculação laboral e aos contextos organizacionais em que desempenham as suas atividades. Uns permanecem em carreiras públicas, ainda que sujeitas às políticas dos últimos anos de contenção na admissão de pessoal e congelamento da progressão da carreira; muitos outros, sobretudo os mais jovens, encontram-se em regime de subcontratação e/ ou a trabalharem em unidades privadas de 
prestação de cuidados de saúde seguido de regras gerais aplicáveis de contratos individuais de trabalho. Assim, assiste-se uma tendência para um assalariamento crescente junto dos diversos grupos profissionais para trabalhos incertos, mal pagos, sem proteção social e sem perspetivas de desenvolvimento de qualificações e de carreira profissional e em condições de trabalho mais intensas e exigentes do ponto de vista do exercício profissional.

As consequências daí decorrentes interpelam-nos para uma discussão em torno das "novas direções" do profissionalismo e os dilemas de regulação nos mercados (trans)nacionais de trabalho, com especial impacto junto de profissionais de saúde, até então com poderes de fixação das suas jurisdições e estratégias de monopólio do mercado de trabalho ${ }^{19,28}$.

\section{Intensificação da crise nos países do Sul da Europa}

De um modo geral, a maior cobertura de saúde e promoção de equidade e justiça social nos países europeus tem sido acompanhado por um aumento nas despesas com a saúde que, em 2016, representou cerca de 9\% do PIB em média ${ }^{27}$ e em 2019 cerca de 9.5\%. Os países do Sul da Europa encontram-se abaixo daquela média na comparação alargada a 35 países, e bastante mais baixa, quando consideramos o investimento público nos países Escandinavos e da Europa Continental. Dada a maior comparticipação pública, os governos têm vindo a preconizar intervenções de promoção da saúde mais rentáveis e que permitam reduzir as desigualdades na saúde (Tabela 1).

Tabela 1. Despesas de saúde em \% do PIB, 2016 (ou ano mais próximo).

\begin{tabular}{llcc}
\hline & Total & Governo/ Obrigatório/ & Voluntário/Despesa privada \\
\hline Alemanha & 11,3 & 9,5 & 1,7 \\
\hline Suécia & 11,0 & 9,2 & 1,8 \\
\hline França & 11,0 & 8,7 & 2,3 \\
\hline Países Baixos & 10,5 & 8,5 & 2,0 \\
\hline Noruega & 10,5 & 8,9 & 1,5 \\
\hline Bélgica & 10,4 & 8,0 & 2,4 \\
\hline Dinamarca & 10,4 & 8,7 & 1,7 \\
\hline Áustria & 10,4 & 7,8 & 2,5 \\
\hline Reino Unido & 9,7 & 7,7 & 2,0 \\
\hline Finlândia & 9,3 & 7,0 & 2,4 \\
\hline OECD35 & 9,0 & 6,5 & 2,5 \\
\hline Espanha & 9,0 & 6,3 & 2,6 \\
\hline Portugal & 8,9 & 5,9 & 3,0 \\
\hline Itália & 8,9 & 6,7 & 2,2 \\
\hline Eslovênia & 8,6 & 6,1 & 2,4 \\
\hline Grécia & 8,3 & 4,8 & 3,5 \\
\hline
\end{tabular}

Fonte: OECD Health Statistics 2017, WHO Global Health Expenditure Database (adaptação nossa)

Sabe-se que o abrandamento económico, a globalização das doenças e das economias e com exigências crescentes para cuidados crónicos, que estão parcialmente ligados ao 
envelhecimento das populações, têm vindo a exigir maior atenção perante o financiamento dos sistemas de saúde.

Igualmente, apesar do reconhecimento do acesso universal e gratuito à saúde para todos os cidadãos, assiste-se a um progressivo aumento da contribuição individual/ familiar no cômputo geral das despesas com saúde (Tabela 2): 23\% na Itália, 24\% na Espanha, $28 \%$ em Portugal e 35\% na Grécia ${ }^{26}$. Esta tendência, além de testar a expansão da privatização dos serviços de saúde, reforça sobretudo a redução da responsabilidade financeira pública com transferência para as famílias e os indivíduos, seja por via da proliferação dos fundos de seguros de saúde, seja pelo aumento das despesas diretas das famílias. Uma das consequências mais imediatas é o agravamento das desigualdades de acesso por parte de segmentos da população com menores condições socioeconómicas.

Tabela 2. Despesas de saúde por tipo de financiamento, 2015 (ou ano mais próximo).

\begin{tabular}{|lcccc}
\hline & $\begin{array}{c}\text { Esquemas governamen- } \\
\text { tais }\end{array}$ & $\begin{array}{c}\text { Seguro de saúde obriga- } \\
\text { tório }\end{array}$ & $\begin{array}{c}\text { Despesa privada } \\
\text { Noruega }\end{array}$ & $\begin{array}{c}\text { Seguro de saúde } \\
\text { voluntário }\end{array}$ \\
\hline Alemanha & 7 & 11 & 14 & 0 \\
\hline Dinamarca & 84 & 78 & 13 & 1 \\
\hline Suécia & 84 & 0 & 14 & 2 \\
\hline Luxemburgo & 9 & 0 & 15 & 1 \\
\hline Islândia & 52 & 73 & 11 & 6 \\
\hline Países Baixos & 9 & 29 & 17 & 0 \\
\hline República Eslovaca & 4 & 71 & 12 & 6 \\
\hline Reino Unido & 80 & 75 & 18 & 0 \\
\hline França & 4 & 0 & 15 & 3 \\
\hline Bélgica & 18 & 75 & 7 & 14 \\
\hline Estônia & 11 & 59 & 18 & 5 \\
\hline Áustria & 31 & 65 & 23 & 0 \\
\hline Itália & 75 & 45 & 18 & 5 \\
\hline Finlândia & 61 & 0 & 23 & 2 \\
\hline OECD35 & 36 & 13 & 20 & 3 \\
\hline Eslovênia & 3 & 36 & 20 & 6 \\
\hline Espanha & 66 & 69 & 13 & 15 \\
\hline Portugal & 65 & 5 & 24 & 4 \\
\hline Grécia & 30 & 1 & 28 & 5 \\
\hline
\end{tabular}

Fonte: OECD Health Statistics 2017 (adaptação nossa).

Ao contrário dos outros países da União Europeia, Portugal, Espanha, Itália e Grécia implementaram cortes em larga escala no emprego público em geral, através da não substituição de reformados, congelamento de novas admissões e/ou demissão de funcionários permanentes, como se verificou na Grécia. As medidas de contração no setor de saúde variaram de congelamentos até cortes severos, com mais impacto naqueles dois primeiros países. Assim, verifica-se que os valores são inferiores não só à média da OECD de 35 
países, como aos países Escandinavos e do Norte da Europa, sendo o seu crescimento em 15 anos manifestamente residual (Tabela 3).

Tabela 3. Emprego em saúde e trabalho social como parte do emprego total, 2000 e 2015 (ou ano mais próximo).

\begin{tabular}{llll}
\hline & Países & $\mathbf{2 0 0 0}$ & $\mathbf{2 0 1 5}$ \\
\hline Noruega & 17,8 & 20,4 & 2014 \\
\hline Dinamarca & 17,3 & 17,9 & \\
\hline Suécia & 16,7 & 16,7 \\
\hline Países Baixos & 12,3 & 15,7 \\
\hline Finlândia & 13,2 & 15,6 \\
\hline França & 12,2 & 14,3 \\
\hline Bélgica & 9,8 & 12,9 \\
\hline Alemanha & 10,4 & 12,8 \\
\hline Reino Unido & 10,1 & 12,4 \\
\hline Irlanda & 7,8 & 12,2 \\
\hline Islândia & & 11,4 \\
\hline Áustria & 8,2 & 10,4 \\
\hline Luxemburgo & 6,7 & 10,2 \\
\hline OCDE 35 & 8,5 & 10,1 \\
\hline Portugal & 5,6 & 7,9 \\
\hline Itália & 6,5 & 7,6 \\
\hline Espanha & 5,3 & 7,0 \\
\hline Grécia & 4,2 & 5,4 \\
\hline
\end{tabular}

Fonte: OECD National Accounts (SNA); Annual Labour Force Statistics (adaptação nossa).

Perante esta pressão de subfinanciamento e privatização do setor da saúde, ficam patentes sinais de reforço de políticas públicas ao nível dos eixos político-normativos de cariz neoliberal.

\section{“Desvalorização” dos profissionais como ajuste à crise}

As implicações das reformas introduzidas no setor da saúde foram muitas, sobretudo vistas como incompletas e introduzindo níveis distintos de atuação por parte do Governo e de complexidade face às dificuldades e desafios que enfrenta ${ }^{29}$.

Analisando os últimos cinco relatórios do Observatório Português dos Sistemas de Saúde (OPSS), tendo em conta ao momento de trabalho de campo, e não considerado o período de crise pandémica por Covid 19, fica patente o agravamento da crise do setor da saúde e, em especial, das desigualdades que têm vindo atravessar o sector da saúde: "Acesso aos cuidados de saúde. Um direito em risco? - Relatório Primavera (2015)"; Saúde: Procuram-se novos caminhos - Relatório Primavera (2016)"; Viver em tempos incertos Sustentabilidade e equidade na saúde - Relatório Primavera (2017)"; "Meio caminho andado - Relatório Primavera (2018)"; "Saúde: um direito humano - Relatório Primavera (2019)" (documentos em linha em http://www.opss.pt/). Também o relatório da Fundação Calouste Gulbenkian, 
designadamente "Um Futuro para a Saúde: todos temos um papel a desempenhar" traça os principais desafios ou dificuldades deste setor. Dos seus conteúdos emergem preocupações comuns quanto aos sinais de uma agenda para a saúde tendencialmente "não-universalista", importada com o impacte no financiamento do Serviço Nacional de Saúde, no PIB do País, à ausência de uma linha clara de orientação no investimento em saúde e no desenvolvimento organizacional do SNS e à desmotivação dos profissionais de saúde, tendência para o "desperdício de talentos" e insatisfação da população mais vulnerável com a resposta do SNS. Sobre este aspeto em particular, atente-se à seguinte passagem:

"(...) os funcionários públicos, incluindo os profissionais de saúde do SNS, tiveram uma redução no seu vencimento de cerca de 15\%, e viram baixar o valor das reformas que terão no futuro. O número de profissionais foi reduzido e, simultaneamente, a procura de cuidados de saúde aumentou. Há enfermeiros desempregados e muitos jovens, assim como alguns profissionais mais idosos, estão a deixar o país e a procurar melhores oportunidades noutros lugares."27

Um dos entrevistados destaca a degradação do Serviço Nacional de Saúde, no que respeita ao nível assistencial e económico:

"Nestes anos de trabalho, para qualquer partido que tenha sido Governo parece apenas importar qual o impacte do financiamento do Serviço Nacional de Saúde, no PIB do País. Não importam os gastos com Parcerias Público Privadas, quer no setor da Saúde como noutros. Não importam desde que diretamente não entrem no Orçamento do Estado. Orçamento esse que terá de ser apresentado na União Europeia e que poderá ser alvo de críticas pelos Parceiros Sociais, trazendo consigo vicissitudes para o país" (E4- Enfermeiro delegado sindical, 40 anos).

Da literatura científica, regista-se, igualmente, as repercussões das reformas introduzidas neste setor particularmente no que diz respeito ao médico, categoria central do sistema de saúde em termos de poder, autonomia e prestígio ${ }^{28}$. Por sua vez, os testemunhos recolhidos permitem aprofundar as repercussões da instabilidade orçamental traduzida nos sucessivos e expressivos cortes no orçamento do Estado, assim como nos salários dos seus profissionais, tendo afetado de forma significativa a vida das instituições, nas suas várias áreas de atuação.

Ao nível da empresarialização dos hospitais, os vínculos contratuais alteraram-se, passando a reger-se pelo contrato individual de trabalho, sendo os seus detentores penalizados em termos de condições de trabalho, com consequências no "clima organizacional", tal como fica patente nos seguintes excertos das entrevistas:

“(...) Penso que o caminho laboral tem sido feito na direção de mais precariedade sob uma capa de flexibilidade, jargões muito em moda como 'produtividade' e 'competitividade' 
desequilibraram a relação laboral em desfavor do trabalhador e muitas vezes ironicamente com o consentimento deste" (E1-Médico, 40 anos).

“(...) no quadro da política Portuguesa apesar do grande investimento em formação existe um claro desinvestimento na carreira destes profissionais que se encontra estagnada há mais de 18 anos. Este desinvestimento verifica-se também no recrutamento, apesar da carência cada vez mais acentuada destes profissionais no SNS" (E3-Técnico de diagnóstico e terapêutica, 50 anos).

Ao nível da profissão de enfermagem registaram-se ainda mais alterações resultantes da revisão da carreira. Refiram-se, por exemplo, à evolução profissional como "uma injustiça contínua", às alterações e estagnação da carreira e às implicações profissionais:

"(...) os enfermeiros ficaram nestes últimos anos sem evolução nenhuma e numa incerteza gigantesca ... o facto de os enfermeiros gestores hoje serem nomeados pelo enfermeiro diretor tira-Ihes também na minha opinião a independência necessário para a defesa diária na criação das condições de segurança e de qualidade nos cuidados" (E5 - Dirigente de uma unidade de cuidados, 42 anos).

"Vejo a minha evolução profissional como uma injustiça contínua. Fiz a minha licenciatura enquanto trabalhava. Investi, quer monetariamente, quer em tempo pessoal, continuamente na formação e atualização profissional. Tenho uma pós-graduação e um mestrado em Ciências de Enfermagem. Com todas as alterações e estagnação da carreira de enfermagem, continuo a ganhar menos que qualquer funcionário público licenciado que integre hoje a função pública. ... Atualmente trabalho numa USF Modelo B. As mudanças no âmbito da reconfiguração dos Cuidados de Saúde Primários (CSP) foram enormes e, na sua maioria, para melhor. Principalmente em termos de estruturas de prestação de cuidados e atendimento, com melhores condições físicas para os utentes e profissionais. $O$ trabalho segundo a metodologia de enfermeiro de família tem objetivos e indicadores de execução melhoraram o acesso dos utentes, implica a reflexão sobre as práticas profissionais e a definição de procedimentos e metodologias de trabalho, envolvendo toda a equipa multidisciplinar. Isto, a meu ver, foi um grande salto qualitativo, no entanto, esta metodologia tem-se traduzido numa carga excessiva de trabalho, (...), implicando trabalhar sempre sobre stress e pressão. Isto tem tido efeito direto sobre as relações interprofissionais, gerando conflitos desnecessários, que ocorrem por desgaste das equipas e dos seus elementos" (E22 - Enfermeira USF Modelo B, 43 anos).

A racionalização neoliberal traduziu-se por mudanças organizacionais neo-taylorianas (racionalização dos percursos dos clientes, centralização da informação, estandardização dos protocolos de cuidados, intensificação do trabalho, cronometragem dos cuidados, sectorização e planificação das atividades dos diferentes prestadores de cuidados), e por 
mudanças do tipo participativo que visavam fazer passar uma lógica compatível com a atividade dos serviços, das patologias rentáveis definidas a partir de uma negociação estratégica sobre a qual repousa o projeto de serviço médico e de enfermagem e de técnicos de gestão terapêutica. O enquadramento dos cuidados é hoje considerado fundamental para a operacionalização e racionalização dos serviços. Também o investimento dos profissionais de saúde em áreas de apoio gestionárias parece ser significativo, quando comparado com o investimento em recursos das áreas técnicas da saúde. Assiste-se também à criação de prémios ranking ao nível nacional entre as instituições, o que faz com que haja uma maior pressão para aumentar os índices de satisfação dos doentes e profissionais. Muitas vezes, os profissionais são incitados pelo alto enquadramento a uma efetiva supervisão dos cuidados. Na opinião da próxima entrevistada, "a Gestão engoliu a Saúde":

“(...) às vezes ... operações de marketing (...) costumo dizer que a Gestão engoliu a Saúde. As decisões e as opções são tomadas por elementos que não são profissionais de saúde. Estes últimos são apenas elementos consultivos e isso faz toda a diferença" (E5 Enfermeira Gestora, 42 anos).

Numa altura em que as exigências nas organizações de saúde são cada vez maiores nem sempre os recursos humanos acompanharam o ritmo das mesmas, quer pelo seu número, quer pela sua formação. São alguns exemplos enunciados, designadamente ao nível de metodologias de trabalho, registos informatizados, processos de gestão e de supervisão, controlo de produção e de custos, entre outros. Algumas passagens dos atores entrevistados são reveladoras destas mudanças:

"Passei pela dificuldade de adaptação aos vários programas informáticos, sem formação adequada, e passei do processo clínico em 2000 totalmente em papel para o actual (...). No lugar do acompanhamento construtivo que antes existia verifica-se um criar de obstáculos para que as equipas não progridam. (...) Quanto ao horário de trabalho desde que passei de interna para especialista que o meu vínculo de 42 horas é ultrapassado. São dadas diariamente horas ao serviço e isso não melhorou nem em UCSP, nem em USF. Penso que só reduzindo a lista de utentes é que o horário poderia ser suficiente para dar resposta, pois cada vez são exigidas mais tarefas ao MF, e maior celeridade na resposta. (...) Os concursos médicos são muito demorados. Integrei um concurso em 2012 para Consultor, cuja prova foi em 2017, e aguardo a publicação do resultado final em DR. O controlo da assiduidade passou do livro de ponto para o controlo biométrico. Não há incremento de produtividade, apenas mais trabalho para o coordenador aquando da validação da assiduidade. Além disso a máquina falha muitas vezes na leitura da digital. O sistema informático é grande gerador de burnout. Várias aplicações diferentes, não interligadas, com palavras-passe diferentes, 
e falha recorrente nas mesmas com impacto muito negativo nas consultas" (E20 - Médica de uma USF, 45 anos)

"Na minha equipa o número de elementos por turno foi reduzido, constituída por 60 Enfermeiros, eu e mais duas pessoas fizemos uma queixa à Ordem dos Enfermeiros decorrente daquilo que seria a redução de horas de cuidados a prestar aos doentes, outrora utentes e agora denominados de 'clientes' da instituição. Não obstante o serviço ter ficado com a redução de elementos fomos trocados de local de trabalho pelo atrevimento" (E4Enfermeiro delegado sindical, 40 anos).

"As mudanças foram muitas - por um lado a introdução das Parcerias Pública e Privada e, por outro lado, o congelamento das carreiras da função Pública. (...) o foco situou-se nos processos de gestão, no controlo de produção, no controlo de custos, na criação e acompanhamento de múltiplos indicadores, trouxe uma nova realidade para os hospitais" (E5 - Enfermeira Gestora, 42 anos).

Há cerca de trinta anos que a totalidade destes agentes tem visto as suas missões, o seu conteúdo funcional e os seus métodos de trabalho transformados. Estes profissionais, também designados por parceiros da direção, são determinantes para a evolução da organização de trabalho. Eles têm por missão afastar projetos transversais (em matéria de equipamento e de orientação terapêutica), e dar soluções em função dos constrangimentos externos (concorrência com outras organizações), perspetivando a evolução da organização do trabalho. Algumas estratégias são concretizadas tais como, reuniões, grupos de projetos, formações em gestão planeadas pelos Centros de Formação que contribuem progressivamente a modificar as práticas e os discursos destes novos parceiros da direção ${ }^{30}$.

O trabalho dos profissionais relacionais é atualmente confrontado com exigências de mudança. Os seus gestores incitam-nos para diversos caminhos (formação, culpabilização, reclamação por parte dos "clientes" ou contribuintes) como forma de renunciar a referência artesanal sobre as quais estavam, frequentemente, pensadas as suas profissões, para passar a uma profissionalidade administrativa. Ao nível do discurso político pretende-se que paralelamente se reúnam esforços de diversas áreas, capazes de gerarem uma nova e homogénea "cultura de enquadramento" e outras formas organizacionais.

\section{- CONCLUSÕES}

As repercussões da crise financeira e das políticas de austeridade inscrevem-se numa tendência longa de subfinanciamento e privatização comuns aos países do Sul da Europa, como vimos. Perspetivar as transformações recentes no setor da saúde em Portugal e no contexto dos países do sul da Europa não prossegue um propósito comparativo, ainda que seja relevante ter em conta os protagonistas e agendas transnacionais neste domínio. O peso 
das instituições, normas e valores que enformam as políticas públicas remete-nos para as especificidades de cada uma das configurações histórico-societais do Estado-Nação. Apesar dos resultados preliminares do presente estudo, o setor da saúde em Portugal enfrenta tensões e desafios comuns aos Estados-membros que passam por: 1) constrangimentos financeiros e cortes significativos nos orçamentos de Estado, sobretudo mais graves em países sobreendividados (como o caso português, sob o memorando de Entendimento da Troika); 2) envelhecimento dos atuais profissionais de saúde e insuficiente/ dificuldades de recrutamento de novos profissionais; 3) problemas de fixação dos profissionais de saúde devido às condições de trabalho e às práticas de baixos salários em algumas das ocupações, conduzindo, em parte, ao fenómeno de "brain drain"/migração num mercado global; 4) emergência de novos padrões de cuidados face às condições crónicas do envelhecimento da população; 5) importância das novas tecnologias na saúde (e.g. e-saúde, telemedicina, plataformas colaborativas) que exigem outras/ novas competências (skill mix) e profissões futuras.

Os profissionais de saúde tentam lutar contra este "desvio", reafirmando, simultaneamente, as missões de uma organização de cariz pública, aberta à população próxima, tais como: oferecer os cuidados de primeira necessidade, que reclama por razões económicas, psicológicas, sociais ou médicas uma hospitalização; apreciar a gravidade dos casos tratados e reorientar para um serviço mais adaptado. Neste sentido, as críticas formuladas ao encontro de uma medicina científica, produtivista e elitista podem ser travadas, mas não conseguem impedir o reagrupamento dos serviços impostos por fações hegemónicas dentro das organizações de saúde, que dão origem às desigualdades - regionais, nos equipamentos e nas ações dos cuidados. As recentes audiências para a saúde parecem não trazer nada de admirável nas suas conclusões, mas põem em evidência dados, por vezes alarmantes, sobre certas fações da população e evocam sem rodeios a falta de eficácia da política sanitária.

\section{- CONTRIBUIÇÕES DAS AUTORAS}

O artigo foi escrito com os contributos compartilhados pelas autoras, com a participação da Ana Paula Marques na pesquisa documental e revisão da literatura e de Rafaela Rosário e Ana Paula Macedo na realização das entrevistas exploratórias e tratamento dos dados. 


\section{- REFERÊNCIAS}

1. Rhodes RAW. The hollowing out of state: the changing natures of public services in Britain. Political Quarterly 1994; 65:138-151.

2. Martins MIC, Marques AP, Costa NR, Matos A. organizadores. Trabalho em Saúde, Desigualdades e Políticas Públicas 2014. E-book; Universidade do Minho Edição CICS-UMinho/ ENSP/ FIOCRUZ. Disponível em: www.lasics.uminho.pt/ojs/index.php/cics_ebooks/issue/view/149/ showToc.

3. Boltanski L, Chiapello È. Le Nouvel Esprit du Capitalisme. Paris: Gallimard; 1999.

4. Wismar M, Maier CB, Glinos IA, Dussault G, Figueras J. editors. Health professional mobility and health systems. Evidence from 17 European countries 2011. World Health Organization 2011, on behalf of the European Observatory on Health Systems and Policies [acessado Nov 14 2017]; Disponível em: http://Health-Professional-Mobility-Health-Systems.pdf.

5. Amaral S, Marques AP. Highly Skilled Portuguese Professionals: Who Are They and What Moves Them Out of the Country? Profiles, Factors and Motivations. European Journal of Social Sciences Education and Research 2017; Vol.9 Nr. 2 (Jan - Apr): 72-86.

6. Bezes PH, Dumazière D. Introduction (dossier-débat): New Public Management et professions dans l'état: au-delà des oppositions, quelles recompositions. Sociologie du Travail 2011; 53: 294-305.

7. Ferrera M. A reconstrução do estado social na Europa meridional. Análise Social 1999; $\left(2^{\circ}-3^{\mathrm{a}}\right)$ : 457-475.

8. Marmot M. Fair society, healthy life. The Marmot review. London: UCL Institute of Health Equity; 2010.

9. European Union. Health inequalities in the EU - final report of consortium. Brussells: European Commission Directorate-General for Health and Consumers; 2013.

10. Organização Mundial de Saúde (OMS). Relatório Mundial da Saúde "Financiamento dos sistemas de saúde. O caminho para a cobertura universal. Genebra: Organização Mundial de Saúde [acessado 16 Dez 2017]; Disponível em http://www.who.int/whr/2010/whr10_pt.pdf; 2015.

11. Santos BS. O Estado, as relações salariais e o bem-estar social na semiperiferia: o caso português. In: Boaventura de Sousa Santos, organizador. Portugal: um retrato singular. Porto: Afrontamento; 1993. p.17-56.

12. Esping-Andersen G. The three worlds of welfare capitalism. Cambridge: Polity Press; 1990.

13. Rhodes M. Southern European welfare: identity, problems and prospects. South Eur Soc Polit 1998; 1:1-22.

14. Andreotti A, García S, Gomez A, Hespanha P, Kazepov Y, Mingione E. Does a southern model exist? Journal of European Area Studies 2001; 9:43-62.

15. Silva PA. O modelo de welfare da Europa do sul. Sociologia, Problemas e Práticas 2002; 38:25-59.

16. Guillén AM, León M. editors. The Spanish welfare state in European context. Farnham: Ashgate; 2011. 
17. Serapioni M. Crise econômica e desigualdades nos sistemas de saúde dos países do Sul da Europa. Cad. Saúde Pública, Rio de Janeiro, v. 33, n.9, e00170116, 2017 [acessado 14 Nov 2017]; Disponível em: http://www.scielo.br/scielo.php?script=sci_arttext\&pi$\underline{d=S 0102-311 X 2017000903001 \& l n g=e n \& n r m=i s o}$

18. Carapinheiro G, Serra H, Correia T. Estado, Medicina e Políticas em Portugal: fluxo e refluxos de poder. In: Alves F, coordenadora. Saúde e Sociedade: uma visão sociológica. Porto: Afrontamento; 2013. p. 49-74.

19. Kuhlmann E, Burau V, Larsen Ch, Lewndowski R, Lionis Ch, Repullo J. Medicine and management in European healthcare systems: how do they matter in the control of clinical practice?. The International Journal of Clinical Practice 2011; 65 (7):222-224.

20. Marques AP, Falleiros I. Metamorfoses na política, valores empresariais e governação em saúde em Portugal. Configurações [Online], vol. 19, pp. 72-88, [acessado 08 Julho 2017]; Disponível em: http://configuracoes.revues.org/4009; DOI : 10.4000/.

21. Teixeira L. A Reforma do Centro de Saúde: Percursos e Discursos. Lisboa: Mundos Sociais; 2012.

22. Esping-Andersen G, Regini M. editors. Why Deregulate Labour Markets?. Oxford: Oxford University Press; 2000.

23. Paugam S. Le Salarié de la Précarité. Paris: PUF; 2000.

24. Marques AP. 'Sacralização' do mercado de trabalho. Jovens diplomados sob o signo da precariedade. Revista Configurações 2010; 7: 65-89.

25. Standing G. The Precariat. The New Dangerous Class. London: Bloomsbury; 2011.

26. OECD. Health at a Glance 2017: OECD Indicators, [acessado 16 Jan 2018]; OECD Publishing, Paris: Disponível em: http://dx.doi.org/10.1787/health_glance-2017-en.

27. Fundação Calouste Gulbenkian. Um Futuro para a Saúde: todos temos um papel a desempenhar. Portugal; 2014 [acessado 14 Nov 2017]; disponível em: https://s3-eu-central-1.amazonaws.com/content.gulbenkian.pt/wp-content/uploads/2016/03/30003652/PGIS_BrochuraRelatorioCompletoHealthPortugues.pdf.

28. Svensson L, Evetts J. editors. Sociology of Professions: continental and anglo-saxon traditions. Goteborg: Bokforlaget Daidalos; 2010.

29. Silva MV. Políticas públicas de saúde: tendências recentes. Sociologia, Problemas e Práticas 2012; 69: 21-128.

30. Macedo A. Supervisão em Enfermagem: Construir as Interfaces entre a Escola e o Hospital. Santo Tirso: De facto Editores; 2012. http://hdl.handle.net/1822/19589. 